\title{
Practical geometallurgy titanium-tantalum-niobates
}

\author{
L. A. Vaisberg, I. D. Ustinov \\ REC «Mekhanobr-Tekhnika», St. Petersburg; gornyi@mtspb.com
}

Fundamental research and geological and mineralogical classification of rare metal deposits conducted since the 1930s with the undoubted priorities of Russian scientists, obtained mainly in works under the direction of A. I. Ginzburg [1]. The largest rare-metal ores in terms of industrial consumption are deposits of titanium-tantalum-niobates containing mineral components - complex oxides of subclasses ABX3, AB2X6, A2B2X7, where $\mathrm{A}$ is $(\mathrm{Na}, \mathrm{Ca}, \mathrm{Fe}, \mathrm{Th}$, $\mathrm{TR}), \mathrm{B}$ is (Ti, Nb, Ta), $\mathrm{X}-(\mathrm{O}, \mathrm{OH}, \mathrm{F})$. Perovskite and loparite are the first subclass, the minerals of the columbite-tantalite series are the second row, and the pyrochlore-microlite minerals are the third row. The deposits of these minerals are mainly of magmatic and post-magmatic origin, often subjected to metasomatism [2]. The decisive fundamental physical and physicochemical properties of these minerals distinguish them from the properties of related minerals, especially their high density (specific gravity) and the strong hydration of their surfaces in an aqueous medium due to the structural features of the upper electronic layers of $\mathrm{Ti}, \mathrm{Ta}, \mathrm{Nb}, \mathrm{Fe}$. Obviously, the high density of the target minerals of rare-metal ores contributes to the implementation of gravitational enrichment processes. Physico-chemical features of the surface impedes their selective flotation. Therefore, the current logic of the through technological corridor of their processing includes gravity methods of concentration of large mineral fractions, flotation of sludge particles with the production of relatively poor concentrates and finishing chemical and metallurgical processing $[3,4]$.

Attention should be paid to the finely disseminated target minerals of a number of promising domestic deposits of titanium-tantalum-niobates. This prevents the implementation of effective and highperformance gravitational schemes for their enrichment.
Studies show that in the presence of carbonate veins (layers) of sufficient power, selective vibrational disintegration of ores, followed by separation in heavy-medium turbocyclones and flotation concentration of a heavy fraction, is a promising way of preliminary dressing. The technology for finely disseminated ores is a combination of reverse flotation with the removal of carbonates of gangue and flotation of titanium-tantalum niobates by complexing collectors in a slightly acidic environment with the intensification of the process using ultrasonic pulp treatment to increase the selectivity of separation of target minerals and iron-containing aluminosilicate minerals. This approach allows, firstly, to use one type of complex-forming flotation reagents-collectors both in the reverse and direct flotation cycle at various $\mathrm{pH}$ values of the flotation pulp, and to realize a full-fledged technological water circulation.

Financial support was provided by the Russian Scientific Fund (project 18-17-00169).

\section{References}

1. Geology of deposits of rare elements, vol. 1, ed. A. I. Ginzburg. M. Gosgeoltekhizdat. 1958. 139 p.

2. Melcher F., Graupner T., Gäbler H.-E., et al. Mineralogical and chemical evolution of tantalum - (niobium - tin) mineralization in pegmatites and granites. Ore Geology Rev. http://dx.doi.org/10.1016/j.oregeorev.2016.03.03.014/.

3. Sidorenko G. A., Alexandrova I. T., Petrova N. V. Technological mineralogy of rare-metal ores. SPb. The science. 1992. $236 \mathrm{p}$.

4. He Jilin, Zhang Zopngguo, Xu Zhongting, et al., Hydrometallugical Extraction of Tantalum and Niobium in China (Tantalum-Niobium International Study Centre (T.I.C.), 1998. Bull. No. 93, p. 1-14. 